\title{
Immunohistochemical and Proteomic Evaluation of Nuclear Ubiquitous Casein and Cyclin-Dependent Kinases Substrate in Invasive Ductal Carcinoma of the Breast
}

\author{
Piotr Ziółkowski, ${ }^{1}$ Elżbieta Gamian, ${ }^{1}$ Beata Osiecka, ${ }^{1}$ Alexandre Zougman, ${ }^{2}$ \\ and Jacek R. Wiśniewski ${ }^{2}$ \\ ${ }^{1}$ Department of Pathology, Wrocław Medical University, 1 Marcinkowskiego Street, 50-368 Wroclaw, Poland \\ ${ }^{2}$ Proteomics and Signal Transduction, Max-Planck Institute for Biochemistry, 82152 Martinsried, Germany \\ Correspondence should be addressed to Piotr Ziółkowski, ziolkows@interia.pl
}

Received 22 February 2009; Revised 5 August 2009; Accepted 6 October 2009

Recommended by George E. Plopper

Nuclear ubiquitous casein and cyclin-dependent kinases substrate (NUCKS) is $27 \mathrm{kDa}$ chromosomal protein of unknown function. Its amino acid composition as well as structure of its DNA binding domain resembles that of high-mobility group A, HMGA proteins. HMGA proteins are associated with various malignancies. Since changes in expression of HMGA are considered as marker of tumor progression, it is possible that similar changes in expression of NUCKS could be useful tool in diagnosis and prognosis of breast cancer. For identification and analysis of NUCKS we used proteomic and histochemical methods. Analysis of patient-matched samples of normal and breast cancer by mass spectrometry revealed elevated levels of NUCKS in protein extracts from ductal breast cancers. We elicited specific antibodies against NUCKS and used them for immunohistochemistry in invasive ductal carcinoma of breast. We found high expression of NUCKS in $84.3 \%$ of cancer cells. We suggest that such overexpression of NUCKS can play significant role in breast cancer biology.

Copyright ( 2009 Piotr Ziółkowski et al. This is an open access article distributed under the Creative Commons Attribution License, which permits unrestricted use, distribution, and reproduction in any medium, provided the original work is properly cited.

\section{Introduction}

Nuclear ubiquitous casein and cyclin-dependent kinases substrate (NUCKS) is a nuclear DNA binding protein occurring in almost all types of human cells, adult and fetal tissues $[1,2]$. The NUCKS gene is located on human chromosome 1q32.1 and consists of seven exons and six introns. It has all the features of being a housekeeping gene [2]. Although its biological function is poorly understood, the structural similarity to the high-mobility group A (HMGA) proteins suggests that it plays a role in regulation of chromatin structure and its activity (for a review see $[3,4]$ ). The HMGA proteins modulate DNA structure altering transcription of several genes by either facilitating or impeding binding of transcription factors [5].

The benign human tumors are mainly of mesenchymal origin and result from chromosomal rearrangements. These include lipomas $[6,7]$, uterine leiomyomas $[8,9]$, and pul- monary chondroid hamartomas [10] or tumors consisting of epithelial and mesenchymal parts like breast fibroadenomas [11]. Rearrangements and overexpression of the $h m g A$ genes were described in nonmesenchymal benign human tumors, such as pituitary adenomas [12]. A high expression of HMGA proteins was observed in all neoplastic tissues analyzed including pancreatic, thyroid, colon, breast, lung, ovarian, uterine cervix and body, prostate, and gastric carcinomas (for review see [4]). High levels of HMGA are also causally related to the neoplastic cell transformation. Finally, HMGA proteins are also involved in hematological neoplasia [13]. It was suggested that HMGAs might be promising targets for therapeutic drugs aimed at alleviating pathological conditions [14]. It is worth mentioning that in normal tissues HMGA protein level is low or even undetectable. Usually, high HMGA expression correlates with bad prognostic factors and metastases. It was assumed that HMGA genes expression might be used as a marker of tumor progression 
[15]; therefore it can also be considered that NUCKS plays a similar practical role in histopathological analysis.

The abundance of NUCKS in rapidly growing cells as well as the overexpression of nucks mRNA in ovarian cancer [16] suggests that it may be involved in facilitating and maintaining activity of transcription of some genes during rapid proliferation and in cancer. Until now NUCKS was studied in detail using a variety biochemical and cell biological methods $[1,2,17-19]$. These analyses however do not relate the occurrence of the protein to histological grade or with a particular cell type. In this work we analyzed the occurrence of NUCKS in breast carcinoma. Using proteomic methods we demonstrated that NUCKS is highly overexpressed in invasive ductal cancer (IDC). Immunohistochemical analysis confirmed this finding and also revealed abundant expression of NUCKS in 26 cases of this cancer. This type was found to be the most frequent malignant tumor of the breast [20] and presents very serious therapeutic and socioeconomical problems. Estimated new cases from breast cancer in the United States in 2008 were 182460 (female) and 1990 (male) and about 41000 deaths (National Cancer Institute; http://www.cancer.gov/cancertopics/types/breast).

\section{Materials and Methods}

2.1. Tissues and Protein Extraction. Samples of IDC of grades II or III were retrieved during surgery. Analysis of the samples followed an informed consent approved by the local ethics committee. The entire protein extraction procedure was carried out as described previously [21]. Briefly, frozen tissue was homogenized with 3 vol. (m/v) of $5 \%(\mathrm{v} / \mathrm{v}) \mathrm{HClO}_{4}$ using an IKA Ultra Turbax blender and the homogenate was centrifuged at $15,000 \times \mathrm{g}$ for 5 minutes. Proteins were precipitated with $33 \%(\mathrm{w} / \mathrm{v}) \mathrm{CCl}_{3} \mathrm{COOH}$ for 30 minutes and collected by centrifugation at $15,000 \times \mathrm{g}$ for 10 minutes.

2.2. SDS-PAGE and Protein Digestion. Aliquots of protein fractions containing NUCKS were separated by SDS-PAGE, using NuPAGE Novex Bis-Tris 4\%-12\% gels (Invitrogen, Carlsbad, CA, USA) and MES running buffer according to the manufacturer's instructions. The gel was stained with Coomassie Blue using Colloidal Blue Staining Kit (Invitrogen).

The NUCKS bands were subjected to a standard ingel trypsin digestion protocol [22]. Briefly, the pieces were washed twice with $25 \mathrm{mM}$ ammonium bicarbonate and dehydrated with absolute ethanol. Subsequently, $0.5 \mu \mathrm{g}$ trypsin (Promega, Madison, WI) solution in $25 \mathrm{mM}$ ammonium bicarbonate was added, and the enzyme was allowed to digest overnight at $37^{\circ} \mathrm{C}$. The peptide mixtures were extracted with $80 \% \mathrm{CH}_{3} \mathrm{CN}, 1 \% \mathrm{CF}_{3} \mathrm{COOH}$ (TFA), and the organic solvent was evaporated in a vacuum centrifuge. The resulting peptide mixtures were desalted using in-house made $\mathrm{C}_{18}$ STAGE tips [23], vacuum-dried, and reconstituted in $0.05 \% \mathrm{CF}_{3} \mathrm{COOH}$ prior to the analysis.

2.3. LC-MS/MS Analysis. Peptide mixtures were separated by online reversed-phase nanoscale capillary liquid chromatography and analyzed by electrospray tandem mass spectrometry as described previously [24]. The data were searched against the full International Protein Index (IPI) database with the aid of the MASCOT (Matrix Science, London, UK) search engine [25] followed by manual verification. All peptides identified from the NUCKS gel bands are listed in the Supplementary Table 1 in Supplementary Material available online at doi:10.115/2009/919645.

2.4. Antibodies. Antibodies against NUCKS were elicited in rabbits using synthetic peptide DEDYGRDSGPPTKKC (residues 23-26) conjugated to ovalbumin (Imject Maleimide Activated Ovalbumin, Pierce). Animals were injected with $0.2 \mathrm{mg}$ of cross-linked peptide. Titer and specificity of the antisera were increased by three injections (boosts).

Monospecific antibodies were purified on affinity columns which were prepared by coupling of the peptide to iodoacetate activated gel (SulfoLink, Pierce) according to the manufacturer's protocol using $1 \mathrm{mg}$ of the peptide per $1 \mathrm{~mL}$ of the coupling gel. The unreacted maleimide groups were quenched with $20 \mathrm{mM}$ cysteine. Then $1 \mathrm{~mL}$ of the gel was loaded into a column and washed with $50 \mathrm{~mL}$ PBS. $5 \mathrm{~mL}$ of the antiserum was diluted with $5 \mathrm{~mL}$ PBS and incubated with the gel for 4 hour. Following washing of the gel with $50 \mathrm{~mL}$ PBS the bound antibodies were eluted with $10 \mathrm{~mL}$ of $0.1 \mathrm{M}$ glycine- $\mathrm{HCl}, \mathrm{pH} 2.5$, and after that with $10 \mathrm{~mL} 4 \mathrm{M}$ guanidine hydrochloride in PBS. The eluates were diluted with $10 \mathrm{~mL}$ of PBS and concentrated in CentriprepUltracel YM-10 (Millipore) concentrators to a volume of $2 \mathrm{~mL}$. The concentrates were dialyzed against PBS overnight. The guanidine hydrochloride fraction of antibodies was used in all experiments.

2.5. Western Blotting. For Western analysis, proteins were transferred from SDS gels onto the nitrocellulose membrane by electroblotting at $10 \mathrm{~V} / \mathrm{cm}$ for $40 \mathrm{~min}$. The proteins were cross-linked to the membrane by incubation in $0.5 \%(\mathrm{v} / \mathrm{v})$ glutaraldehyde in PBS for $10 \mathrm{~min}$. The membranes were blocked with $10 \%$ (v/v) normal goat serum (NGS) for $30 \mathrm{~min}$ prior to incubation with the primary antibodies together with $1 \%$ NGS in PBS containing $0.1 \%$ Tween 20 (PBS-T). The concentration of the primary antibodies was $1.5 \mu \mathrm{g} / \mathrm{mL}$. Following 2 hour incubation, the membrane was extensively washed with PBS-T. Primary antibodies were visualized on the membrane with ECL peroxidase-conjugated IgGs. After the detection of antibodies blots were stained with Amido Black stain (Sigma, St Louis, MO).

2.6. Histopathology. 26 samples of breast cancer, derived from 26 different female patients, were investigated in this experiment. In particular, this was the invasive ductal carcinoma (IDC) of grade (G) I (10 cases), II (6 cases), and III (10 cases). Cancer was excised during radical mastectomy or tumorectomy depending on the result of the previously performed imaging studies, fine-needle aspiration biopsy, oligobiopsy, or intraoperative diagnosis.

The samples from the tumors were fixed in $4 \%$ formalin and embedded in paraffin. After that, the paraffin blocks were cut on microtome to obtain $4 \mu \mathrm{m}$ thick slices which were mounted on glass slides and stained with hematoxylin-eosin (HE) or with antibodies. Evaluation of HE-stained samples 
was performed by use of light microscope (OLYMPUS BX50) at magnification 100 or 200 times.

2.7. Immunohistochemical Staining. Following deparaffinization the antigen determinant was retrieved using normal pressure cooking in $0.01 \mathrm{M}$ sodium citrate for 9 minutes in $350 \mathrm{~W}$ microwave oven at $\mathrm{pH} 6$. The slides were blocked for endogenous peroxidase (Peroxidase Blocking Reagent, DAKO Cytomation) and incubated overnight with antiNUCKS antibodies at concentration of $15 \mu \mathrm{g} / \mathrm{mL}$ in PBS containing 125 -fold diluted swine serum at $4^{\circ} \mathrm{C}$. The binding of the primary antibodies was visualized using the $\mathrm{ABC}$ method (kit LSAB, DAKO Cytomation) and stained with DAB (DAKO). The PBS was used on each step. Finally, the slides were counterstained with hematoxylin and rinsed in tap water.

Percentage of positively stained cancer cells was evaluated on 5 fields from the centre of tumor: number of positively stained cells (nuclei and cytoplasm) was divided by the total number of cancer cells seen on that field at magnification of 400 times. A mean value from 5 such fields is shown in "results" section. The selection criterion for the 5 fields measured was the centre of each sample and this was assessed by two pathologists. We also evaluated staining in other cells: lymphocytes and endothelial cells used as positive control because it was suggested that NUCKS is localized in both proliferating and nonproliferating cells [18]. Negative control obtained by omitting the primary antibody.

The microphotographs were taken using light microscope (OLYMPUS BX40) at magnification 200 times and digital camera DP10. Two independent pathologists evaluated each slide. Statistical analysis of correlation between histological grading and number of positively stained cells was made. ANOVA one-way analysis of variance by ranks was used for this statistical analysis.

\section{Results}

3.1. NUCKS Is Highly Overexpressed in Ductal Invasive Breast Cancer. A group of nuclear proteins including linker histones $\mathrm{H} 1$ and HMG proteins can be selectively extracted from cells and tissues with diluted perchloric acid [21]. NUCKS also can quantitatively be extracted using 5\% perchloric acid. To compare the levels of NUCKS in human cancer and nondiseased tissues we extracted the protein from five pairs of matched diseased and normal samples, from 5 patients, and analyzed its abundance on SDS gels. The identity of the NUCKS-band was analyzed by mass spectrometric analysis. We found that in each of the five cases NUCK was the only abundant component of the stained gel-band. All identified peptides with their precursor ion accuracy and Mascot scores are listed in Supplementary Table 1.

We found that the band of NUCKS with a relative Mr of 43,000 occurred abundantly in all samples of IDC, whereas in all normal samples either it did not appear or the band was very weak (Figure 1). The levels of NUCKS in IDC were comparable with those in cultured breast cancer cells MCF7. Since overexpression of NUCKS in ovarian
TABLE 1: The NUCKS positive staining in cells of invasive ductal carcinoma (in \%) with relation to histological grading (I-II-III).

\begin{tabular}{lcc}
\hline Grade & Number of cases & \% stained cell (SD) \\
\hline I & 10 & $77.5(5.36)$ \\
II & 6 & $85.5(4.59)$ \\
III & 10 & $89.6(3.47)$ \\
Total & 26 & 84.3 \\
\hline
\end{tabular}

cancer was recently described [16], we analyzed also ovarian cancer sample and found similar extent of upregulation of NUCKS in this type of cancer in comparison to IDC. From this experiment we concluded that NUCKS is highly overexpressed in IDC and we decided to study its occurrence in more detail.

3.2. Generation of Polyclonal Monospecific Antibodies against NUCKS. To investigate the occurrence of NUCKS in cells and tissues, antibodies against a peptide corresponding to residues 23-36 of the protein were elicited in rabbits and were affinity purified. The specificity of the antibodies was analyzed on western blots using purified NUCKS, perchloric acid extracts and whole SDS whole lysates of MCF7 cells, and IDC and normal breast tissue (Figure 2). The blots revealed that our antibodies decorated selectively the band of NUCKS, indicating the high specificity of the antibodies. Western analyses using other lysates and extracts of human tissue and cells resulted in identical results (not shown).

\subsection{Histochemical Analysis of NUCKS in Invasive Ductal} Carcinoma. The study comprised 26 cases of invasive ductal carcinoma (IDC). They were first evaluated with regard to histopathology (grading) and then the samples from particular tumors were studied using immunohistochemical method. The occurrence of NUCKS was observed in tumor cells as well as in other cells seen in samples, like endothelia and lymphocytes.

In invasive ductal carcinoma, IDC (carcinoma ductale infiltrans), the positive staining of cytoplasm was rather less intensive than that of nuclei (Figure 3, with an inset). The cytoplasmic staining in IDC cells is shown in Figure 4 (with an inset). The number of stained cells, both nuclei and cytoplasm, ranged from $77.5 \%$ of cancer cells in group of grade I (Figure 5) to $89.6 \%$ in the group of grade III (mean: $84.3 \%$, for the whole group of 26 cases, see Table 1 ). A low number of lymphocytes which formed inflammatory infiltration at the border of tumor foci showed positive nuclear reaction (Figure 6). Positive nuclear reaction was also observed in endothelial cells. Negative control is shown in Figure 7, while Figure 8 shows fat tissue from the IDC patient at a morphologically normal site away from the lesions without any immunohistochemical reaction.

Considering the significance level, $\alpha=0.05$, we can confirm statistically significant difference between group of GI cancers and GII $(P=.00235)$ and also between GI and GIII $(P=.000004)$, whereas there was no significant difference between groups GII and GIII $(P=.0931)$ (Figure 9 and Table 2). 


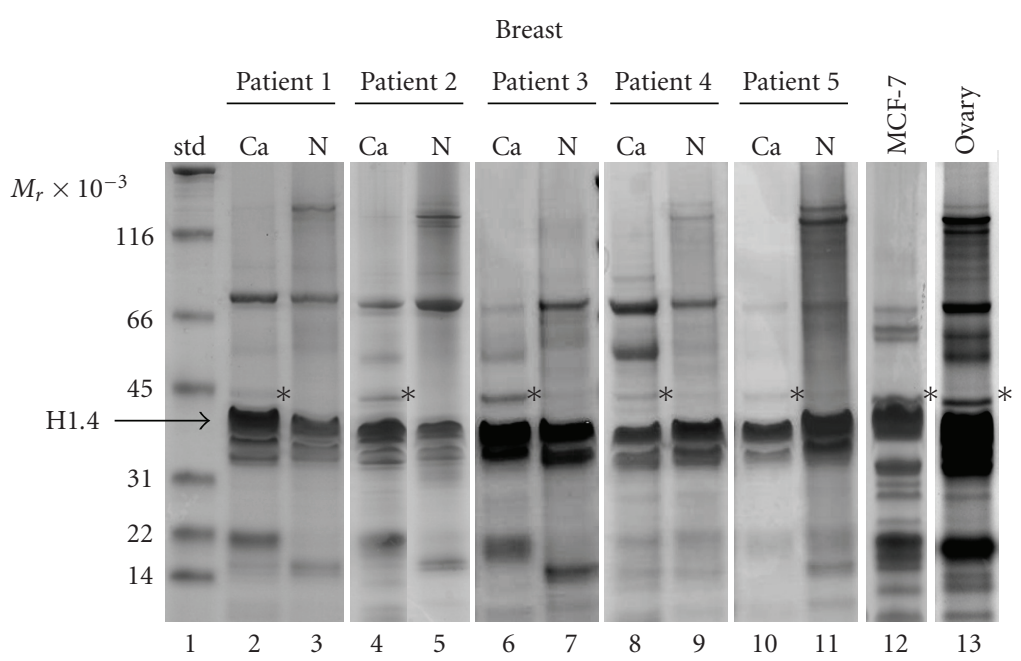

FIGURE 1: NUCKS is highly overexpressed in breast cancer. Lanes 2-11: Protein extracts from five pairs of tissue, each pair matching the individual patient, of normal breast $(\mathrm{N})$ and invasive ductal carcinoma GII (Ca) were separated by SDS-PAGE and stained with Coomassie. Lanes 1, 12, and 13: molecular weight standard and proteins extracts of MCF7 cells and an ovarian tumor, respectively. Asterisks indicate the position of NUCKS band. $M_{r}$ : relative molecular weight. The band of linker histone H1.4 (arrow), a highly abundant housekeeping protein, serves a "gel loading" control. Its intensity is similar in lanes of normal breast, IDC, and MCF7 cells lysates. Identity of the H1.4 band was confirmed by mass spectrometry (Figure 1).

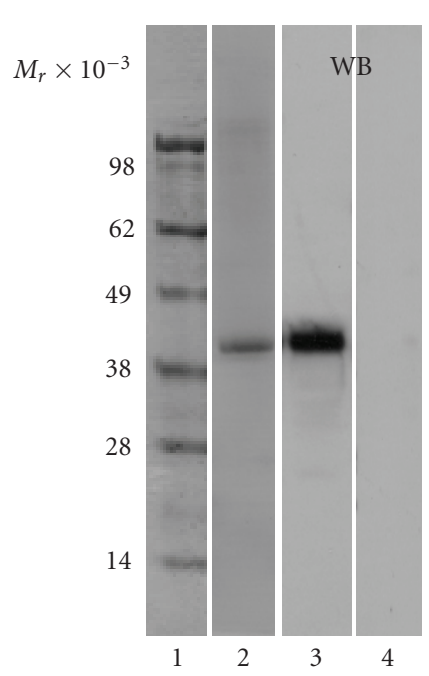

(a) Purified NUCKS

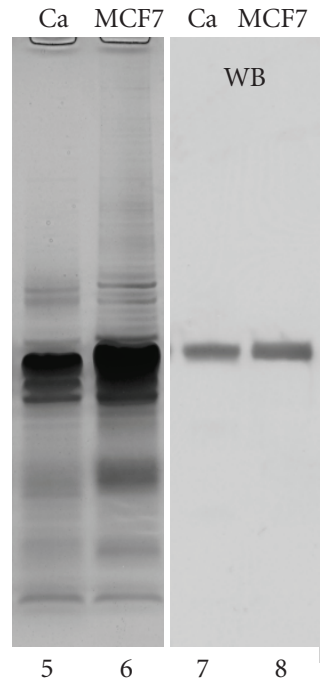

(b) $\mathrm{HClO}_{4}$ extracts

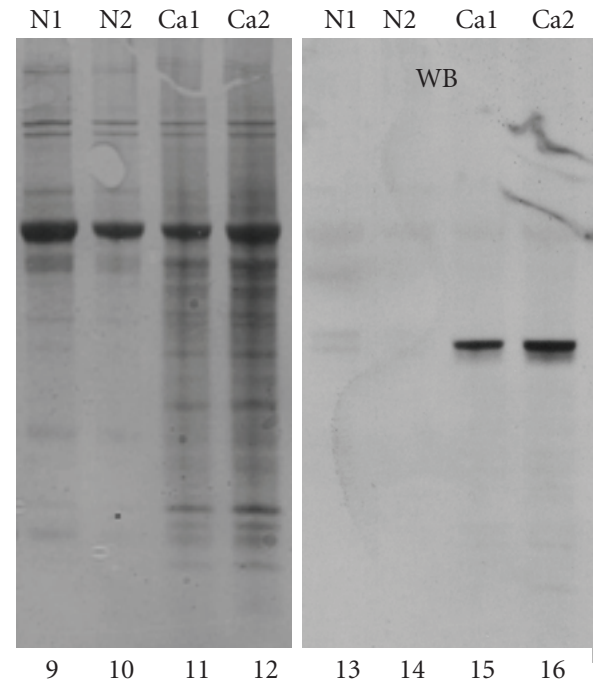

(c) SDS total lystates

FIGURE 2: Specificity of the antibodies elicited against NUCKS' peptide: Purified NUCKS ((a) lanes 2-4), HClO4-extracts invasive ductal carcinoma GII (Ca in (b): lanes 5 and 7) and MCF 7 cells ((b): lanes 6 and 8), and SDS-total lysates of normal breast (N: lanes 9, 10, 13, 14) and invasive ductal carcinoma GII (Ca in (c): lanes 11, 12, 15, 16) each matching the same patient (c) were separated by SDS-PAGE, blotted onto nitrocellulose and incubated with affinity purified anti-NUCKS antibodies. Lane 4: the antibodies were preincubated with the peptide used for antibody production and purification. Total protein was stained on blots with Amido Black (lanes 1, 2, 5, 6, and 9-12).

\section{Discussion}

Until now NUCKS was studied in detail using a variety of biochemical and cell biological methods $[1,2,17,18]$. However, these analyses did not correlate with the occurrence of the protein in particular type of cancer and/or type of cells. In this study the occurrence of NUCKS in human breast cancer was studied. Using the proteomic approach we demonstrated that NUCKS is overexpressed in tumor cells. Histochemical analyses revealed positive staining for NUCKS with different frequencies. The observed expression of NUCKS in cancer cells was found in all examined cases. There are some unpublished reports confirming NUCKS presentation in both cellular compartments, that is, nuclei 


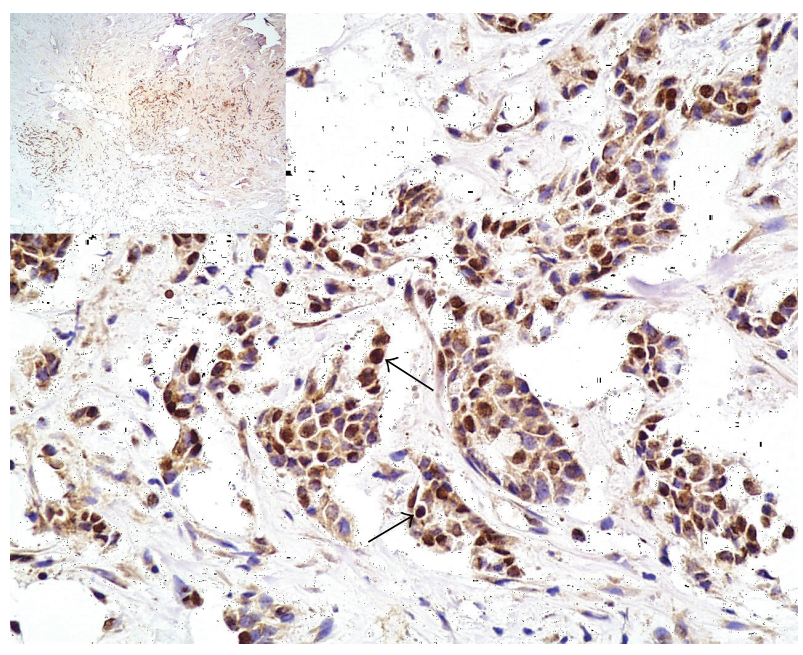

FIgURE 3: Occurrence of NUCKS in invasive ductal carcinoma, G III. The positive reaction was found in majority of tumor cells with prevalence of nuclear staining (arrows and brown color). The nuclei negative for NUCKS are stained blue or dark blue. ABC method. Magnification 200x, inset 40x.

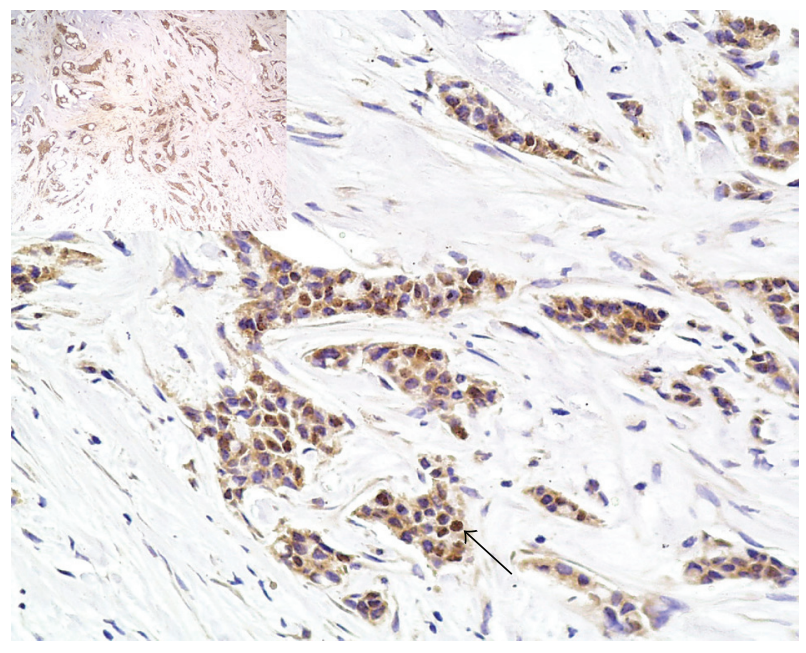

Figure 4: Occurrence of NUCKS in invasive ductal carcinoma, GII. The positive staining in this case was less frequent than that in the case shown in Figure 3. Some cells show also faint cytoplasmic parallel to nuclear reaction. ABC method. Magnification 200x, inset 40x.

TABle 2: Comparison of $P$-values between G groups.

\begin{tabular}{llll}
\hline & & & $P$-value \\
\hline GI & versus & GII & .002352 \\
GI & versus & GIII & .000004 \\
GII & versus & GIII & .093116 \\
\hline
\end{tabular}

and cytoplasm. The importance of NUCKS remains still unknown and disputable.

NUCKS has 2 regions termed as nuclear localization signals (NLSs) where NLS1 is assumed to be main nuclear localization signal that binds to importin $\alpha 3$ and $\alpha 5$ in vitro

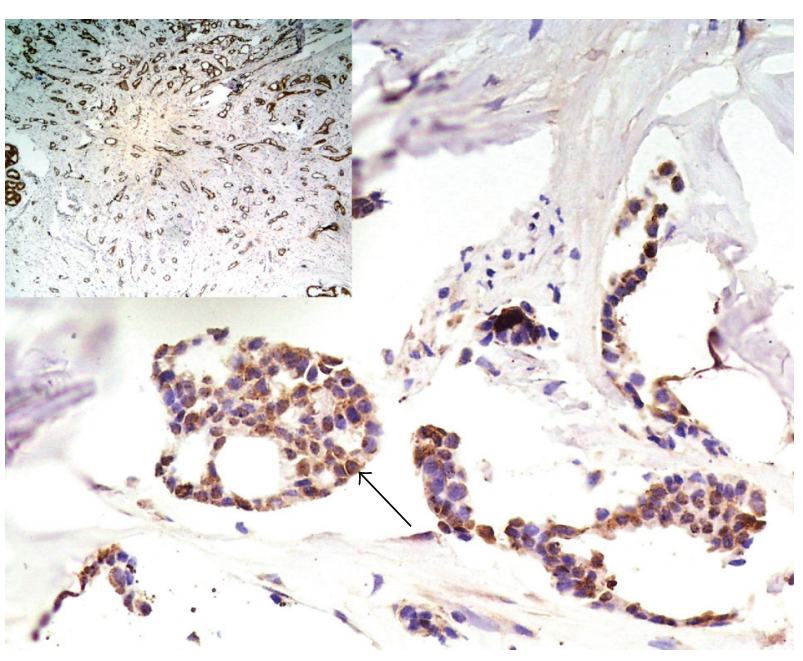

FIGURE 5: Occurrence of NUCKS in invasive ductal carcinoma, GI. The positive staining in this case was the least frequent in comparison to cases of IDC GII and GIII. ABC method. Magnification 200x, inset 40x.

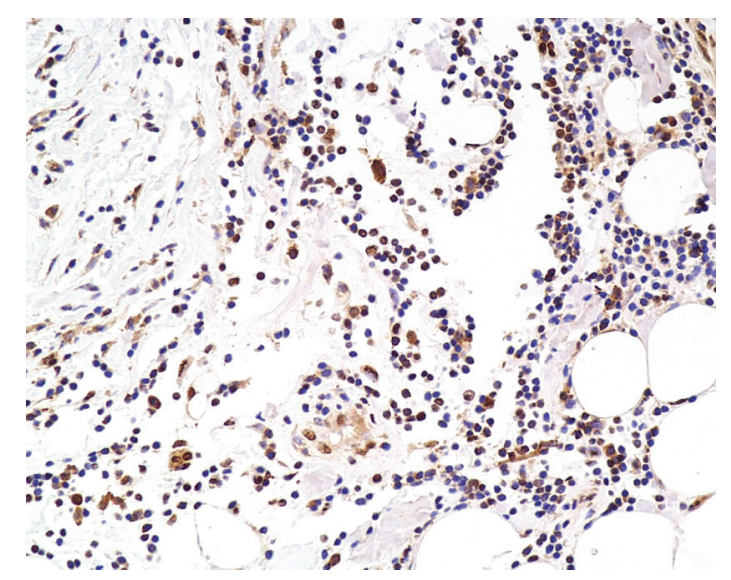

FIgURe 6: Positive control for NUCKS. This was obtained using positive reaction for NUCKS in lymphocytes from an inflammatory infiltration at the border of invasive ductal carcinoma. ABC method. Magnification 200x.

[18]. Importin is in turn a protein which after binding with NLS moves the other proteins into nuclei. This movement between two compartments may probably play an important role in some phenomena leading to protection of a cell against undesirable factors. The varied expression of NUCKS in our study may reflect the well-known heterogeneity of cells in breast cancer, which was confirmed for Ki67 reactivity [26]. The Ki67 activity was higher in ductal cancer and lower in mucinous and lobular carcinoma. In other studies it was found that using the Van Nuys grading system of worst grade, the grade of tumor was not associated with either ductal carcinoma in situ recurrence or development of invasive disease [27]. There is also evidence that invasive breast cancer is the disease with multiple cytogenetic subclones already present in preinvasive lesions [28]. 


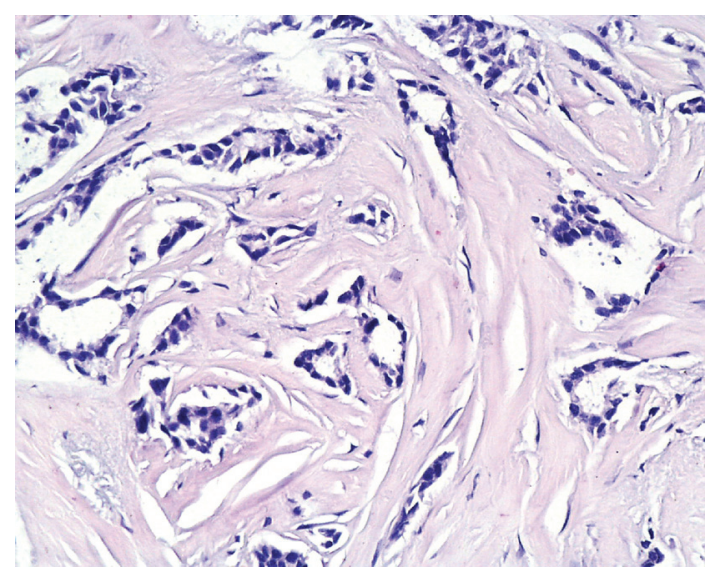

Figure 7: Negative control. This was obtained by omitting the primary antibody. The sample is from invasive ductal carcinoma, GII. Sample is counterstained with HE. Magnification 200x.

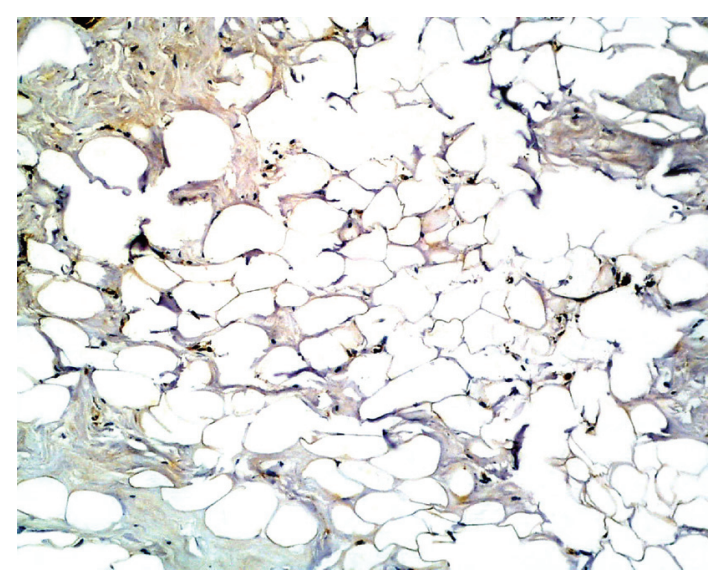

FIGURE 8: Normal breast. This figure presents the fat tissue from the IDC patient at a morphologically normal site away from the lesions which showed no reaction to anti-NUCKS antibody. ABC method, Magnification 200x.

Grade III tumors were found to manifest high levels of several genes involved in regulation of gene expression including NUCKS [1]. In our study we observed correlation between NUCKS expression and histological grading. Statistically significant differences were found between group of GI and GII cancers and also between GI and GIII, whereas there was no significant difference between groups GII and GIII.

The NUCKS was reported to localize in both proliferating and nonproliferating cells: positive staining for NUCKS was found in our study in endothelial cells and lymphocytes. Since endothelial cells and lymphocytes belong to the relatively fast growing cells or at least they show high metabolism, overexpression of NUCKS is probably related to high levels of transcription.

In our study the positive staining was mainly observed in nuclei of tumor cells and nuclei of normal cells. Mixed nuclear and cytoplasmic reaction, which was seen in cells of IDC, may reflect known distribution of NUCKS throughout

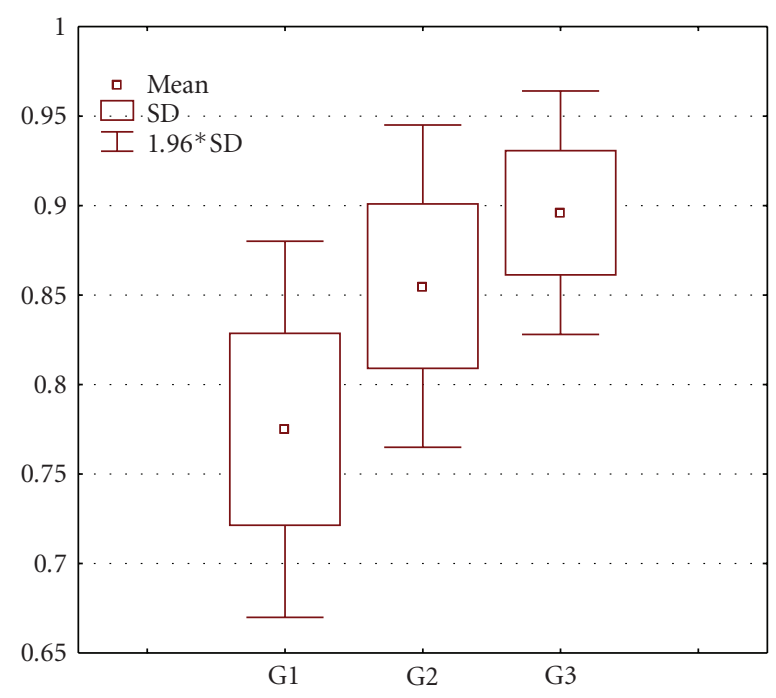

FIGURE 9: Posthoc test results of the least significant differences, LSD, between different groups of cancer with regard to grading (axis $\mathrm{X}$-groups, axis Y-fractions of stained cells).

the cytoplasm in mitotic cells whereas nuclear localization of NUCKS is connected with telophase of cellular cycle [18].

Previously, the expression of the high-mobility group protein gene $h m g A 2$ and its protein as a possible marker detecting malignant growth of thyroid tumors was used [15]. Whereas HMGA2 is highly expressed in most embryonic tissues, its expression in adult tissues is very low. However, reactivation of expression was described for various malignant tumors and correlated with aggressiveness of tumors. Since HMGA2 expression alone allowed to distinguish between benign and malignant thyroid tumors with sensitivity of $95.9 \%$ and specificity $93.9 \%$, we assume that by similarities between HMGAs and NUCKS the latter as well might be used as a marker in histological evaluation of tissues. NUCKS was previously reported to be expressed in breast, for example, in lobular carcinoma, and ovarian cancers as a part of a module containing at least six members that are believed to be involved in either transcriptional regulation or ubiquitin proteasome pathway [29].

Recently, the elevated expression of DYRK3, NUCKS, COX-2, and translin and tubulin- $\alpha 4$ genes, which are involved in proliferation and inhibition of apoptosis and cell movement, was found to be associated with high-invasive phenotype in mouse lung adenocarcinoma cell strains [30]. Statistically significant increase in the expression of transcripts for tubulin- $\alpha 4$, COX-2, DYRK3, and translin was associated there with amplification of mouse chromosome 1. The NUCKS protein was increased in the majority of the cell strains [30].

In conclusion, it has to be emphasized that further studies are needed to determine a role of NUCKS in human cancer and that this work provides only early insights in the abundant occurrence of the protein in breast cancer. The future work also should pay additional attention in elucidating potential functions of specific posttranslational 
modifications of NUCKS [19] in etiology and progression of the disease.

\section{Acknowledgments}

The authors thank Dr. M. Mann for continuous support and interest. The work was funded by: Wrocław Medical University, Poland, and Max-Planck Society.

\section{References}

[1] A. C. Stvold, J. H. Norum, S. Mathiesen, B. Wanvik, I. Sefland, and K. Grundt, "Molecular cloning of a mammalian nuclear phosphoprotein NUCKS, which serves as a substrate for Cdk1 in vivo," European Journal of Biochemistry, vol. 268, no. 8, pp. 2430-2440, 2001.

[2] K. Grundt, I. V. Haga, V. Aleporou-Marinou, Y. Drosos, B. Wanvik, and A. C. Østvold, "Characterisation of the NUCKS gene on human chromosome 1q32.1 and the presence of a homologous gene in different species," Biochemical and Biophysical Research Communications, vol. 323, no. 3, pp. 796801, 2004.

[3] J. R. Wiśniewski and R. Schwanbeck, "High mobility group I/Y: multifunctional chromosomal proteins causally involved in tumor progression and malignant transformation (review)," International Journal of Molecular Medicine, vol. 6, no. 4, pp. 409-419, 2000.

[4] A. Fusco and M. Fedele, "Roles of HMGA proteins in cancer," Nature Reviews Cancer, vol. 7, no. 12, pp. 899-910, 2007.

[5] R. Reeves and L. Beckerbauer, "HMGI/Y proteins: flexible regulators of transcription and chromatin structure," Biochimica et Biophysica Acta, vol. 1519, no. 1-2, pp. 13-29, 2001.

[6] H. R. Ashar, M. S. Fejzo, A. Tkachenko, et al., "Disruption of the architectural factor HMGI-C: DNA-binding AT hook motifs fused in lipomas to distinct transcriptional regulatory domains," Cell, vol. 82, no. 1, pp. 57-65, 1995.

[7] E. F. Schoenmakers, S. Wanschura, R. Mols, J. Bullerdiek, H. Van den Berghe, and W. J. M. Van de Ven, "Recurrent rearrangements in the high mobility group protein gene, HMGI-C, in benign mesenchymal tumours," Nature Genetics, vol. 10, no. 4, pp. 436-444, 1995.

[8] S. Heim, M. Nilbert, R. Vanni, et al., "A specific translocation, $\mathrm{t}(12 ; 14)$ (q14-15;q23-24), characterizes a subgroup of uterine leiomyomas," Cancer Genetics and Cytogenetics, vol. 32, no. 1, pp. 13-17, 1988.

[9] Y. Hennig, P. Rogalla, S. Wanschura, et al., "HMGIC expressed in a uterine leiomyoma with a deletion of the long arm of chromosome 7 along with a 12q14-15 rearrangement but not in tumors showing del(7) as the sole cytogenetic abnormality," Cancer Genetics and Cytogenetics, vol. 96, no. 2, pp. 129-133, 1997.

[10] B. Kazmierczak, J. Rosigkeit, S. Wanschura, et al., "HMGI$\mathrm{C}$ rearrangements as the molecular basis for the majority of pulmonary chondroid hamartomas: a survey of 30 tumors," Oncogene, vol. 12, no. 3, pp. 515-521, 1996.

[11] B. Staats, U. Bonk, S. Wanschura, et al., "A fibroadenoma with a $\mathrm{t}(4 ; 12)$ (q27;q15) affecting the HMGI-C gene, a member of the high mobility group protein gene family," Breast Cancer Research and Treatment, vol. 38, no. 3, pp. 299-303, 1996.
[12] G. M. Pierantoni, P. Finelli, E. Valtorta, D. Giardino, O. Rodeschini, and F. Esposito, "High-mobility group A2 gene expression is frequently induced in non-functioning pituitary adenomas (NFPAs), even in the absence of chromosome 12 polysomy," Endocrine-Related Cancer, vol. 12, no. 4, pp. 867874, 2005.

[13] G. M. Pierantoni, V. Agosti, M. Fedele, et al., "High-mobility group A1 proteins are overexpressed in human leukaemias," Biochemical Journal, vol. 372, no. 1, pp. 145-150, 2003.

[14] R. Reeves and L. M. Beckerbauer, "HMGA proteins as therapeutic drug targets," Progress in Cell Cycle Research, vol. 5, pp. 279-286, 2003.

[15] G. Belge, A. Meyer, M. Klemke, et al., "Upregulation of HMGA2 in thyroid carcinomas: a novel molecular marker to distinguish between benign and malignant follicular neoplasias," Genes Chromosomes and Cancer, vol. 47, no. 1, pp. 56-63, 2008.

[16] M. E. Schaner, D. T. Ross, G. Ciaravino, et al., "Gene expression patterns in ovarian carcinomas," Molecular Biology of the Cell, vol. 14, no. 11, pp. 4376-4386, 2003.

[17] K. Grundt, L. Skjeldal, H. W. Anthonsen, T. Skauge, H. S. Huitfeldt, and A. C. Østvold, "A putative DNA-binding domain in the NUCKS protein," Archives of Biochemistry and Biophysics, vol. 407, no. 2, pp. 168-175, 2002.

[18] K. Grundt, I. V. Haga, H. S. Huitfeldt, and A. C. Østvold, "Identification and characterization of two putative nuclear localization signals (NLS) in the DNA-binding protein NUCKS," Biochimica et Biophysica Acta, vol. 1773, no. 9, pp. 1398-1406, 2007.

[19] J. R. Wiśniewski, A. Zougman, S. Krüger, et al., "Constitutive and dynamic phosphorylation and acetylation sites on NUCKS, a hypermodified nuclear protein, studied by quantitative proteomics," Proteins, vol. 73, no. 3, pp. 710-718, 2008.

[20] M. Trojani, A Color Atlas of Breast Histopathology, J. B. Lippincott, Philadelphia, Pa, USA, 1991.

[21] A. Zougman and J. R. Wiśniewski, "Beyond linker histones and high mobility group proteins: global profiling of perchloric acid soluble proteins," Journal of Proteome Research, vol. 5, no. 4, pp. 925-934, 2006.

[22] A. Shevchenko, M. Wilm, O. Vorm, and M. Mann, "Mass spectrometric sequencing of proteins from silver-stained polyacrylamide gels," Analytical Chemistry, vol. 68, no. 5, pp. 850-858, 1996.

[23] J. Rappsilber, Y. Ishihama, and M. Mann, "Stop and go extraction tips for matrix-assisted laser desorption/ionization, nanoelectrospray, and LC/MS sample pretreatment in proteomics," Analytical Chemistry, vol. 75, no. 3, pp. 663-670, 2003.

[24] J. R. Wiśniewski, A. Zougman, S. Krüger, and M. Mann, "Mass spectrometric mapping of linker histone $\mathrm{H} 1$ variants reveals multiple acetylations, methylations, and phosphorylation as well as differences between cell culture and tissue," Molecular and Cellular Proteomics, vol. 6, no. 1, pp. 72-87, 2007.

[25] D. N. Perkins, D. J. C. Pappin, D. M. Creasy, and J. S. Cottrell, "Probability-based protein identification by searching sequence databases using mass spectrometry data," Electrophoresis, vol. 20, no. 18, pp. 3551-3567, 1999.

[26] V. Kuenen-Boumeester, T. H. Van der Kwast, H. A. J. Van Laarhoven, and S. C. Henzen-Logmans, "Ki-67 staining in histological subtypes of breast carcinoma and fine needle aspiration smears," Journal of Clinical Pathology, vol. 44, no. 3, pp. 208-210, 1991. 
[27] N. A. Miller, J.-A. Chapman, E. B. Fish, et al., "In situ duct carcinoma of the breast: clinical and histopathologic factors and association with recurrent carcinoma," Breast Journal, vol. 7, no. 5, pp. 292-302, 2001.

[28] H. Buerger, R. Simon, K.-L. Schafer, et al., "Genetic relation of lobular carcinoma in situ, ductal carcinoma in situ, and associated invasive carcinoma of the breast," Molecular Pathology, vol. 53, no. 3, pp. 118-121, 2000.

[29] H. G. R. Thompson, J. W. Harris, B. J. Wold, S. R. Quake, and J. P. Brody, "Identification and confirmation of a module of coexpressed genes," Genome Research, vol. 12, no. 10, pp. 1517-1522, 2002.

[30] L. M. Sargent, M. X. Ensell, A.-C. Ostvold, et al., "Chromosomal changes in high- and low-invasive mouse lung adenocarcinoma cell strains derived from early passage mouse lung adenocarcinoma cell strains," Toxicology and Applied Pharmacology, vol. 233, no. 1, pp. 81-91, 2008. 

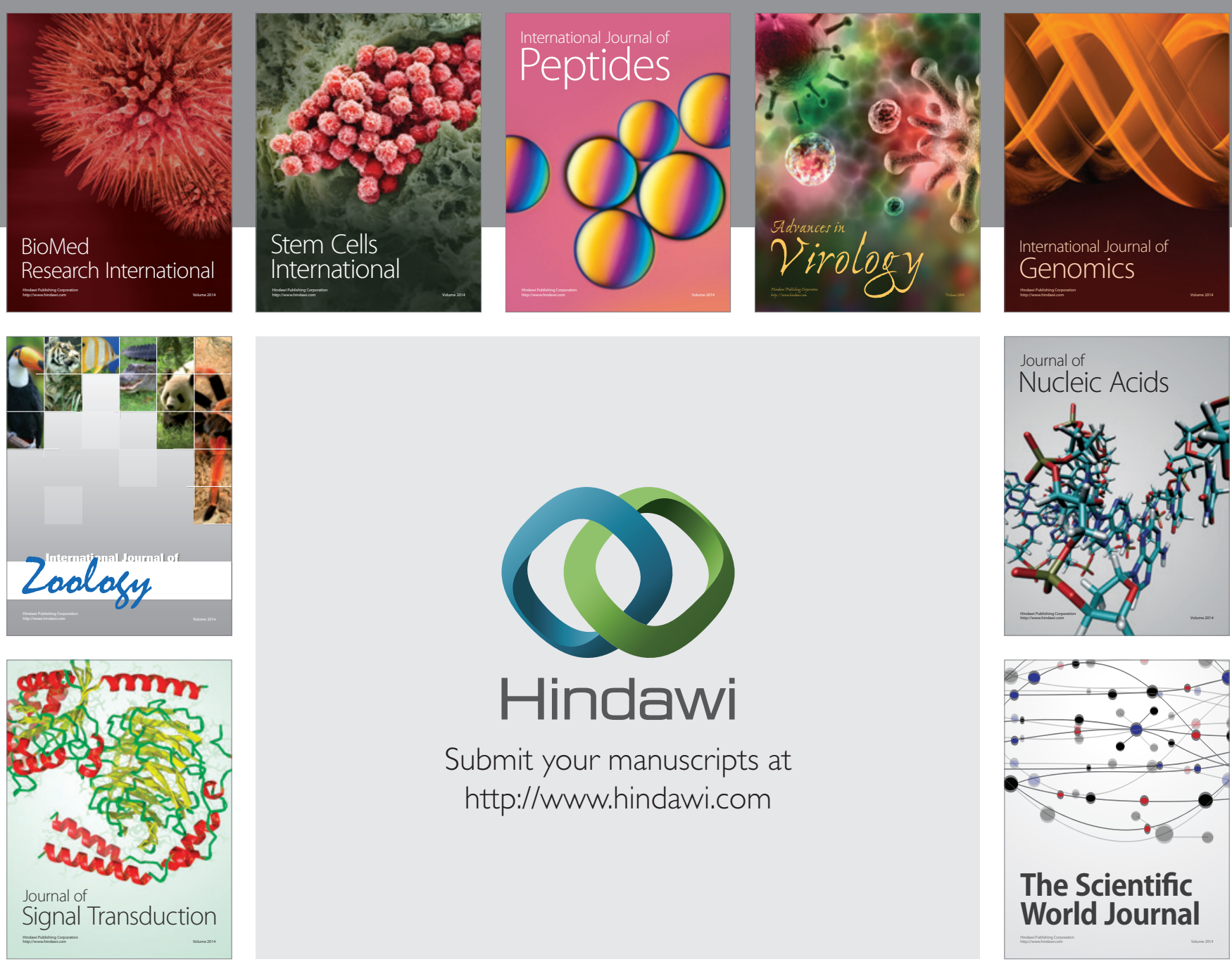

Submit your manuscripts at

http://www.hindawi.com
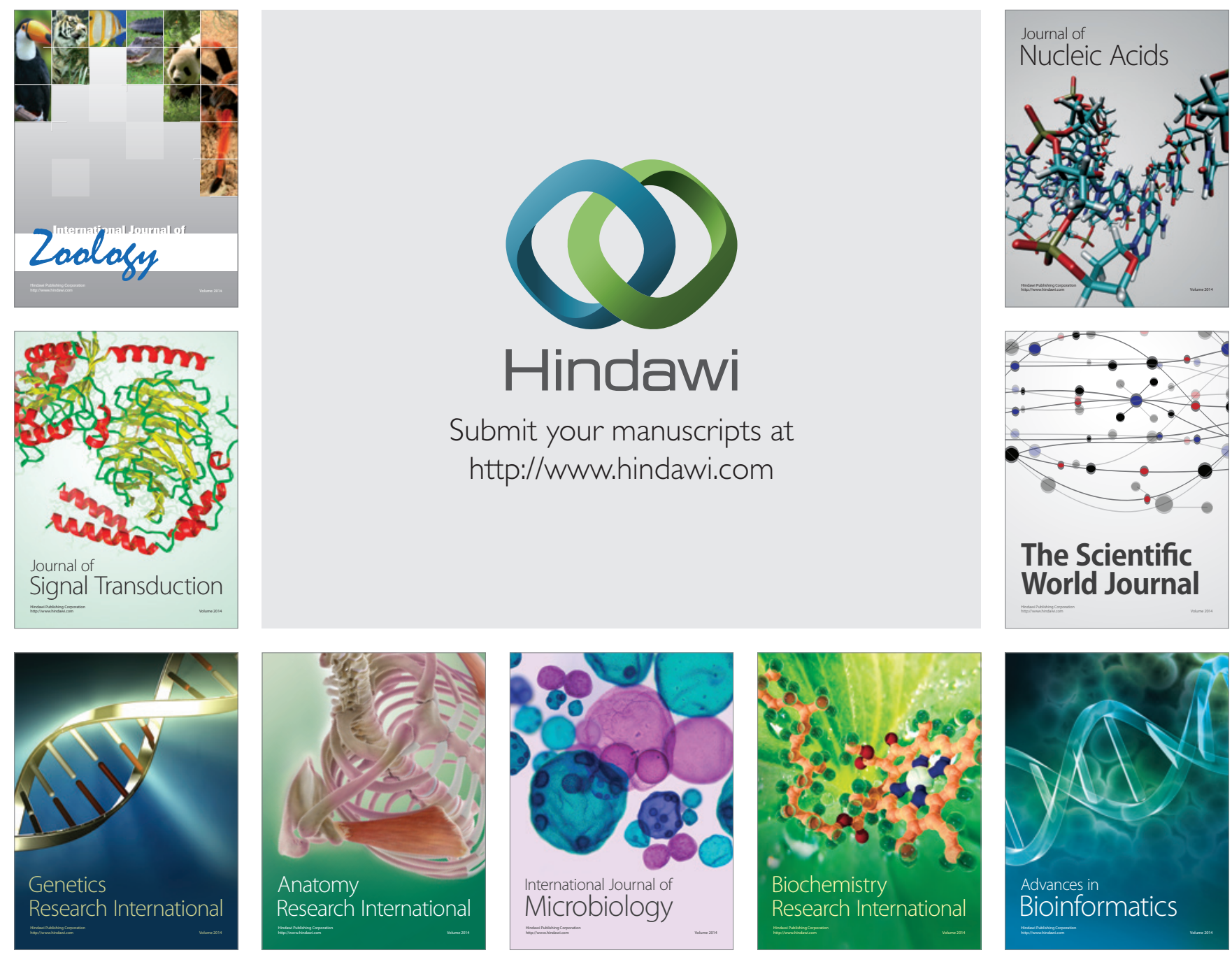

The Scientific World Journal
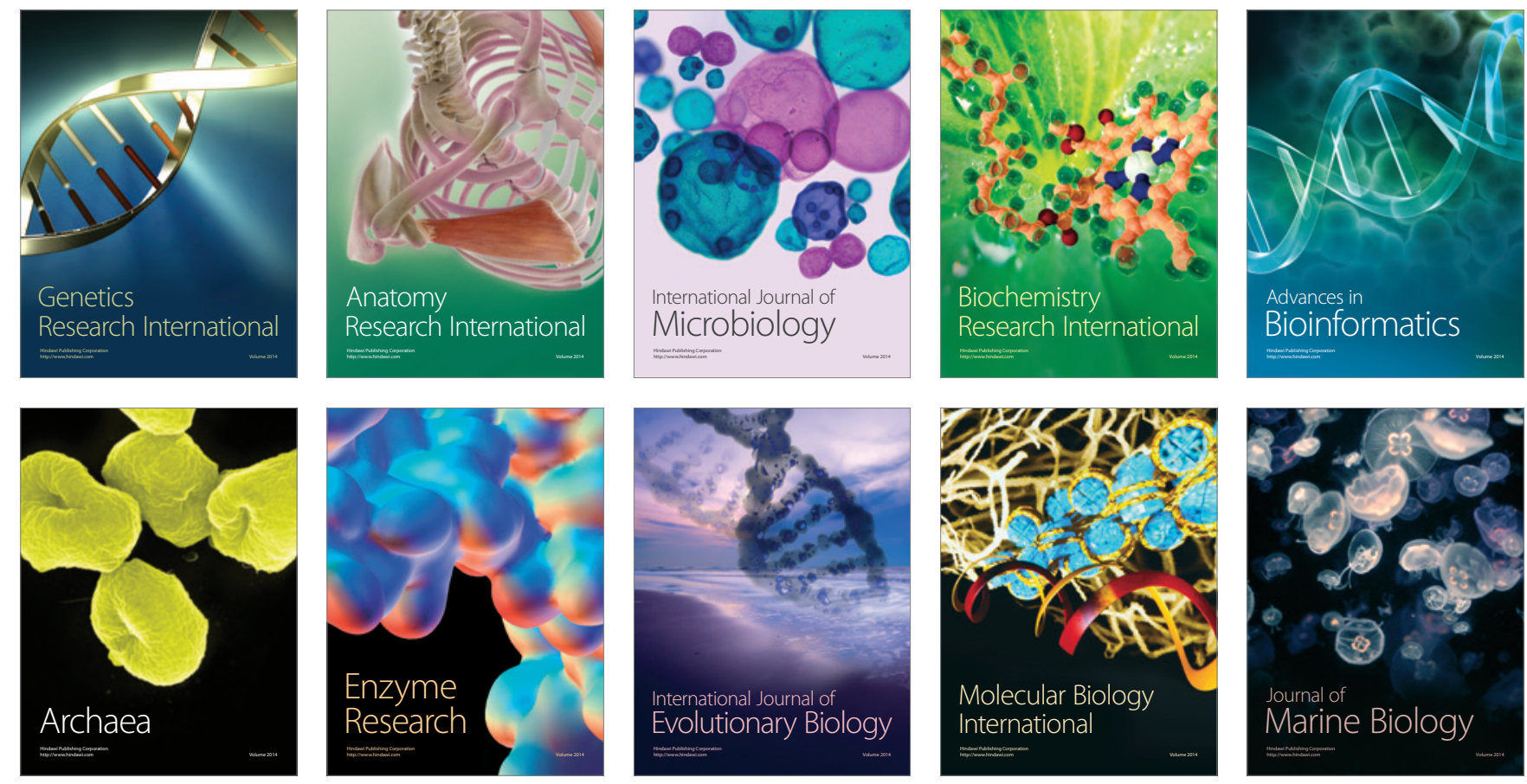